Fecha de recepción: noviembre 2020

Fecha de aprobación: diciembre 2020

Fecha publicación: marzo 2021

\section{La moda en el museo. El caso de la moda argentina}

Lorena Pérez ${ }^{(1)}$

Resumen: La moda tuvo una aparición más frecuente en los museos y espacios destinados a la exhibición de arte en los últimos años. En las muestras de moda se recopila, exhibe e investiga la cultura del pasado y del presente. Este ensayo narra el interés de los museos por la moda y pone en contexto la experiencia de la moda argentina, con referencias a las exhibiciones de Fridl Loos, Dalila Puzzovio, Mary Tapia, Gino Bogani, el movimiento under, la generación de diseño de autor y el caso de Malba Moda a modo de explorar el potencial de la moda en los museos para reflexionar la historia a través de las épocas y sus creadores.

Palabras clave: moda - arte - museo - comunicación de moda - Argentina - autor - diseño - historia - creadores - exposiciones.

[Resúmenes en inglés y portugués en las páginas 116-117]

(1) Periodista especializada en Periodismo Digital por la Universidad de San Andrés y Universidad Nacional de San Martín. Fundadora de Blocdemoda.com (2006) un medio digital pionero de cultura-moda.

\title{
Introducción
}

Los museos de todo el mundo ofrecen importantes exhibiciones de moda, también galerías de arte e instituciones. Por lo tanto, las muestras de moda hoy son omnipresentes. La evolución de este fenómeno global tiene su antecedente en Estados Unidos en la década de 1970 y su momento de mayor repercusión con la muestra de Alexander McQueen Savage Beauty (2011), y hacia 2015 el fenómeno estaba consolidado luego de la inauguración de China: through the looking glass (2015). En este período, la moda en el museo batió récord de recaudación y visitas. Todo esto aconteció en el Metropolitan Museum de Nueva York, el espacio donde se dio la evolución de las muestras de moda que imperan en la actualidad. El origen fue en 1973, cuando Diana Vreeland, al dejar su puesto en la revista Vogue, asumió como consultora en el Costume Institute y presentó como primera muestra una 
retrospectiva de Cristobal Balenciaga, luego de la muerte del modisto. Así sucedieron sus célebres exhibiciones de moda, aclamadas y denostadas en partes iguales. "La tendencia de la señora Vreeland para hacer pasar fantasías exhuberantes por exposiciones históricas en museos de arte es penosa e inapropiada" (Silverman, 1986, p. 11).

En 1948, la publicista Eleanor Lambert realizó un evento benéfico en el MET y lo llamó "La fiesta del año". En 1937 abrió el Museum of Costume Art que más tarde, en 1946, se fusionó con el Museo Metropolitano de Arte como The Costume Institute, el sitio donde en la actualidad se desarrollan las muestras de primavera bajo el paraguas de la revista Vogue, al mando hoy de Anna Wintour, que además tiene un documental sobre el tema: The First Monday in May (2016). Diana Vreeland fue la editora que dio la sustancia al fenómeno al ofrecer una muestra que señaló el inicio de una etapa de aceptación para la moda como un arte decorativo y como parte del patrimonio cultural. Es preciso señalar la importancia de las muestras inteligentes y con interpretación histórica montadas en el Victoria \& Albert Museum de Londres, Palais Galliera de París y el FIT de New York. "La creciente sofisticación visual del público que va al museo incrementa aún más la importancia del diseño en el montaje de una exposición" (Steele, 2008, pp. 7-30).

Para una casa de moda, hace cincuenta años, archivar no era una práctica habitual, por lo que la donación de diseños fue la vía para armar las muestras con clientas devenidas en coleccionistas. Recuperar las piezas en un archivo no era parte de las tareas esenciales de las diseñadores porque el objetivo siempre fue y es venderlas. Sin embargo, hoy parte del patrimonio creativo se archiva. El hábito de poner a resguardo los procesos que componen una colección es costoso y demanda un tiempo que los creativos no tienen. Muchas cosas se pierden, otras se encuentran de maneras inesperadas más el factor sorpresa de toparse con material que nadie buscaba. El fenómeno surgido en el año 2010 alrededor de las muestras de moda en los museos inyectó el interés de los diseñadores por conservar su historia, pues ya no es necesario retirarse para levantar una exhibición (Perez, 2018). El factor museo transformó la forma en que los diseñadores tratan a sus propios archivos. En el nuevo milenio, las marcas y los grupos financieros que compraron gran parte de las maisons tradicionales comenzaron a destinar un presupuesto al archivo y abrir, incluso, sus propios museos y fundaciones. Salvatore Ferragamo, Dior, Yves Saint Laurent, Prada, Louis Vuitton, Balenciaga y Max Mara son algunas de las firmas que lo hicieron. Valentino Garavani se convirtió en un precursor de las exposiciones exclusivamente digitales. Junto a su compañero y socio Giancarlo Giammetti y la actriz Anne Hathaway, en 2011 ofrecieron una conferencia de prensa transmitida en vivo por Youtube para presentar el Museo Virtual Valentino Garavani, una app que exploraba la historia del modisto.

\section{¿Para qué sirve una muestra de moda?}

El caso es que se puede hablar del creador, la maison, su historia y savoir faire. El furor de las exposiciones que los museos destinan a la moda es uno de los reflejos de lo que sucedió con la moda en sí misma en este siglo, cuando dejó de ser un tema de pocos para convertirse en un entretenimiento que convoca a una gran audiencia. Así, la moda es ayudada 
por las innovaciones tecnológicas y las imágenes instantáneas que dinamizan el pasado para ofrecer un nuevo impulso visual en constante evolución. "La moda en los museos ahora está interesada no en el objetivo de la moda, sino en un análisis basado en imágenes de los fenómenos de la moda y la escenografía espectacular que ilustran visualmente una narrativa analítica" (Melchior, 2014, p. 2).

\section{Caso de estudio: la moda argentina en el museo}

Las muestras de moda son una práctica frecuente en la escena local. Las exposiciones aquí señaladas corresponden a exhibiciones donde es posible trazar una línea temporal para contar la historia de la moda argentina desde el siglo XX con las singularidades de cada período y los reflejos según la época.

\section{Artistas, diseñadores y moda}

La moda fue parte de la transformación dada por la contracultura juvenil en los años 60 que surgió en Londres y destronó a la Alta Costura de París. Los jóvenes diseñadores ingleses, sus boutiques y los nuevos estilos modificaron la estructura de la moda y lograron la misma atención que las maisons francesas: por primera vez se veneraba la juventud y sus estéticas (Perez, 2020). La moda en Londres, el Mayo Francés y la escena hippie en Estados Unidos tuvo su correlato en Buenos Aires a través del Instituto Di Tella como punto neurálgico de esta revolución que incluía el vestir. El objetivo del Di Tella fue promover el estudio, la investigación y así contribuir a la promoción de artistas. Eran pocos los lugares donde sucedían las cosas en esta década, por eso este emblemático espacio ofició de punto de encuentro a través de los tres centros de arte que funcionaban en Florida 936, en la zona conocida como La Manzana Loca y donde también estaba ubicada la Galería del Este. Los artistas del movimiento de arte pop fueron los que construyeron la historia de este instituto, algunos de ellos cruzaron el arte con la moda. Esta línea histórica contada a través de exposiciones de moda en espacios destinados al arte comienza con la obra emblemática Dalila Doble Plataforma presentada en el Instituto Di Tella. En 1967, Dalila Puzzovio compitió en el Premio Internacional Di Tella con esta obra que identificó su carrera. Para imaginar el siglo XXI, la artista construyó las plataformas en estructuras de metal e intervino el cuero en colores flúor -algo inédito en esa época- y le ofreció la producción a Alberto Grimoldi para comercializarlas en las tiendas de la firma en la calle Florida, Avenida Santa Fe y el barrio de Belgrano. La obra de arte fue expuesta en el Di Tella como una experiencia de consumo e incluía la visita del jurado del premio a los locales para evaluar la obra. Por aquellos días, Pierre Restany (1967), el crítico de arte francés y gran conocedor de la obra de Dalila, dijo que la obra de Puzzovio "adquiere sentido en la corriente de vitalismo urbano de la época" y resaltaba que Buenos Aires había encontrado el lenguaje existencial de su modernidad en el pop lunfardo y ensalzaba la cultura porteña con el floreciente diseño porque mixturaba el objeto de arte y el objeto utilitario. 
En el Di Tella sucedieron otros acontecimientos que cruzaron el arte con la moda, como la realización del desfile Ropa con riesgo (1968) de Delia Cancela y Pablo Mesejan y Pachamama Prêt-à-porter (1969) de Mary Tapia, diseñadora que además realizó su primer desfile en Buenos Aires en la galería de arte El Laberinto (1966).

\section{Las vanguardias en la moda argentina}

En el año 2000, el Centro Cultural Recoleta presentó la Exposición homenaje a Fridl Loos - Alta Costura. Fotogramas. Pinturas que contó con la misma artista como curadora, fallecida un mes antes de la inauguración. Fridl Loos era austríaca y se radicó en Argentina en los años 40' junto al arquitecto Walter Loos, su marido, huyendo de la guerra. Al hacer un safari por el Noroeste argentino quedó deslumbrada por los textiles y materiales autóctonos y los incorporó a su estética como diseñadora. Fridl Loos diseñó textiles, hizo vestuarios para cine y teatro. Absorbió las vanguardias de las primeras décadas del siglo XX. En los años 20, formó su visión estética en la escuela de Arte de Viena con Josepf Hoffman. Su trabajo en la moda es más de una artista que de una modista y eso fue lo que reflejó la exposición. Según manifestó, en Buenos Aires era más conocida por su moda, por ese motivo en 1999 comenzó la gestión para realizar una muestra en el Recoleta.

En Buenos Aires, Fridl Loos comenzó a diseñar para la casa Drecoll, una de las tiendas que colmaban Buenos Aires con alta costura y viajaban a París en busca de inspiración, y como ya no podían trasladarse a Europa al comenzar la Segunda Guerra Mundial "fue un buen momento para emprender algo nuevo. También en esa época Harrods importó una gran cantidad de telas de la India y compré un stock importante para mis modelos" (Loos, 1999, p. 19). Abrió su primer local frente a la plaza San Martín a principios de la década del ‘50, financiado por la actriz Delia Garces, una de sus clientas. Sus vidrieras novedosas llamaron la atención de una compradora del almacén Neiman Marcus, quien le pidió una colección de estilo argentino para vender en Estados Unidos.

Era una persona de enorme talento: creaba cosas muy nuevas, como tailleurs de patchwork o batik marmoleado estampado sobre seda -sus propios diseños textiles- que aquí no se habían visto. Pequeñita, siempre impecable y encantadora, era también una gran artesana y conocía la técnica de crear para el cine. No utilizaba los brillos de la época sino que interpretaba la ropa para el personaje, que además eran modelos espléndidos, muy bien hechos. Recuerdo un vestido de hilo, muy simple, cosido a mano con una costura de Hermès, y un tailleur fantástico, con bolsillos y todo, pero sin mangas, usado sobre una camisa. Quedaba lindisimo. También un traje de gamuza color beige, que hoy sería usual, pero hace 40 años era toda una novedad, cosido totalmente a mano. Su ropa no llamaba la atención, no pegaba gritos, pero era una maravilla (Garcés, 1999, p. 19).

En la exposición hubo diseños de los años 40', como una falda patchwork, un pantalón y una blusa inspirada en el gaucho, series de fotogramas, collages y dibujos de su obra plásti- 
ca que registran su vida de artista. Se retiró cuando falleció su esposo Walter, en 1973. Fridl Loos murió el 24 de junio de 2000. La muestra homenaje se inauguró un mes después en la Sala J del Centro Cultural Recoleta.

\section{Una mujer para darle identidad a la moda argentina}

Íntima, Mary Tapia (2018) fue una muestra autobiográfica levantada en el Museo del Traje con piezas del patrimonio personal de la diseñadora, hoy al resguardo de su hija Eva Zanada, Bimba y prendas que prestaron compradoras, amigas y más diseños que pertenecen al museo. El legado de Mary Tapia fue reconocido por el compromiso en representar la identidad criolla en sus ropas. El estilo folk que impregnaron sus diseños fueron confeccionados con materiales autóctonos, como el barracán, el aguayo y la chagua, y coloreados con tintes naturales. Mezcló texturas del noroeste argentino y otras técnicas artesanales latinoamericanas, como el Ao Po'i de Paraguay y el picote de Ecuador en sus diseños numerados.

La primera sala de la muestra en el Museo del Traje ofreció una réplica del taller de Mary Tapia, con la vitrina y el espejo que le pertenecieron. Acompañaba una máquina de coser, los retazos de tela, el costurero... En otra sala había percheros con las prendas numeradas de Mary Tapia y contiguo una vitrina con material histórico con fotografías de sus desfiles, reseñas de las colecciones, más escritos de la periodista Felisa Pinto y la investigadora María Laura Carrascal. El recorrido por la muestra abarcó todas las salas del museo finalizando con el trabajo de Tota Reciclados, el proyecto de Marcela Muñiz y Valeria Hasse, basado en el reciclado de materiales de descarte: Mary Tapia les donó una bolsa con telas para que hagan joyería. Así, cuellos, prendedores y bolsos se lucieron en maniquíes. Mary Tapia falleció en 2011. En 2006 el Museo de Arte Latinoamericano de Buenos Aires le dedicó una retrospectiva a sus 40 años de trayectoria a través de la exposición Moda con Identidad Criolla, mientras que su legado expuesto en el Museo del Traje fue una constante en guiones que buscaron recuperar los orígenes de la moda en Argentina. Por ejemplo la muestra Pioneras del diseño en Argentina: Mary Tapia (1936-2011), Fridl Loos (1905-2000) y Medora Manero (1922-2011). El Museo de la Historia del Traje de Buenos Aires fue fundado en 1972 y su acervo está conformado por más de 9000 piezas que abarcan desde el siglo XVIII hasta la actualidad. Allí se puede encontrar trajes típicos de varios países como Grecia, Japón o China, trajes de novia de todas las épocas e indumentaria de personalidades del mundo del espectáculo.

\section{Del modisto al diseño autoral}

La exageración y alta moda que signó la década de 1980, en Buenos Aires se reflejó con grandes desfiles en los hoteles a cargo de los modistos, quienes aplicaban las técnicas de la Alta Costura, y las boutiques, tiendas comandadas por mujeres que interpretaban las ideas del prêt-à-porter a prendas fáciles de usar. Ambas categorías eran el síntoma de cómo se vestían las mujeres y no contemplaba a la moda juvenil: ser joven en los ' 80 significaba 
hacerse el look, porque las marcas jóvenes comenzaron a fundarse hacia finales de esta década. La ropa en Argentina se vinculaba a replicar las tendencias y estilos que llegaban de las capitales productoras, como París, New York y Roma. Como bisagra, hubo un hecho fundamental que mostró el cambio cultural que rompió con lo que significaba la moda hasta ese momento. En 1989 se lleva a cabo la Primera Bienal de Arte Joven, organizada por la Subsecretaría de la Juventud de la Municipalidad de la Ciudad de Buenos Aires. La moda ingresó como disciplina artística a la vez que visualizó lo que sucedía en la contracultura under porteña. Estos creadores presentaron sus desfiles en la plaza San Martín de Tours, frente al Centro Cultural Recoleta. De ese puñado de chicos menores de 30 años sobresalieron Andrés Baño, Gabriel Grippo y Gabi Bunader: ellos habilitaron una forma nueva para hacer moda en Argentina, incluso antes de que existiera la carrera en la Facultad Arquitectura, Diseño y Urbanismo, lanzada ese mismo año. Sus shows en la Bienal fueron inspiradores para otros creadores que a partir de este acto decidieron insertarse en el lenguaje de la moda, tal el caso de Sergio De Loof.

De Loof fue un artista multifacético, videasta, ambientador, creador de lugares que se convirtieron en marcas de época, como el Bar Bolivia, El Dorado, Morocco. Como diseñador trabajó con modos de producción que incluían al reciclaje y la visita al cottolengo. El Museo de Arte Moderno de Buenos Aires dedicó una antología a Sergio De Loof llamada ¿Sentiste hablar de mí? (2019), curada por Lucrecia Palacios y con la incidencia del propio artista, quien hasta su muerte en marzo de 2020 difundió a través de la red social Facebook el armado y estreno de su exhibición. El archivo del artista quedó en custodia de la Fundación Investigación en Diseño Argentino, en la era de los videoclips, Sergio De Loof registró todo en cassettes VHS que fueron restaurados por el Museo del Cine para su muestra en el museo y el Complejo Teatral de Buenos Aires, el Teatro Argentino de La Plata y el Museo de la Ciudad ayudaron ambientar el espíritu de las noches de los 90's que incluía en la sala la réplica de vestidos que no fueron conservados: vestidos de papel madera, otros confeccionados con las páginas de la revista Vogue y también en pluribol. Cabe destacar que ¿Sentiste hablar de mí? Hizo foco en el trabajo de De Loof, pero tal como sucedía en los ' 90 , esta camada de diseñadores se movilizaba en grupo. Tiempo antes, el Centro Cultural Recoleta inauguró De Gino Bogani al diseño de autor (2013), una muestra que iluminó los años ' 50 de trabajo del gran modisto argentino.

La libertad de ideas para diseñar de Gabi Bunader, Gabriel Grippo y Andrés Baño al que luego se sumaron De Loof, Kelo Romero, Cristian Dios y Pablo Simón dio sustancia al nuevo diseño y con sus métodos de trabajo relacionados al reciclaje anticiparon la transformación del sistema de la moda y estaban en sintonía con la obra del diseñador belga Martin Margiela. La exhibición De Gino Bogani al diseño de autor apenas destinó una tarima bajo el nombre Generación Under para mostrar los vestuarios de estos diseñadores realizados con materiales de descarte que eran personalizados para ser usados como canal de expresión, por lo que sigue estando en falta una retrospectiva que legitime la visión de estos vanguardistas.

"Gino Bogani es el referente de la alta costura argentina, el primero en ser considerado como un diseñador celebridad” (Catálogo, 2013, p. 6). Más de cinco décadas dedicadas al diseño, Bogani implementó el cruce con el arte en busca de inspiración para sus colecciones. Trazó alianzas con el Museo de Arte Moderno y el Museo de Bellas Artes para utilizar 
su acervo y realizar desfiles en sus instalaciones, la muestra en el Recoleta rescató vestidos de distintas décadas.

El señor Gino Bogani, quien ha sido elegido por su larga trayectoria, prestigio, vigencia y presencia en su hacer actual. Fue él quien vistió con elegancia la mujer argentina desde los 60 s, así como también a varias de las divas del ambiente artístico; y es él quien como legítimo descendiente de la alta escuela europea tiene privilegio de cuidar con distinción la imagen de varias generaciones de mujeres que visten su obra, donde volúmenes, siluetas, materiales, cromatismos y texturas con impecables acabados que son parte de su firma (Moragues, 2013, p. 5).

Aún así, Bogani afirmó no comprender el sentido de la muestra, que combinó la esencia de diversos diseñadores, modistos y empresarios textiles separados en las categorías Generación Under, Diseño de Autor y Diseño Emergente bajo una misma muestra, reflejando así la mentalidad de la moda argentina de convocar al concepto de diseñador para todo aquel que trabaje con ropa.

\section{El nuevo milenio}

Universos de Moda (2014) fue una muestra en la Colección de Arte Amalia Fortabat con la curaduría a cargo de Vicky Salías y reunió dos camadas de diseñadores con el fin de mostrar sus procesos de trabajo. Desde la metodología y apelando a símbolos, invocados en el primer piso del espacio de arte ubicado en Puerto Madero en mesas de trabajo y un maniquí expuesto con algunos de los modelos emblemas de las doce etiquetas seleccionadas. Ellas fueron: Cora Groppo, Cecilia Gadea, Laura Valenzuela, Vicky Otero, Mariana Dappiano, Marcelo Senra, Tramando, Juana de Arco, Vero Ivaldi, Kostume, Garza Lobos y Bandoleiro. "Universos de moda se propone desentrañar los modos discursivos de los diseñadores de moda local de los últimos quince años. Modos que se inscriben, desde lo metodológico, en los procedimientos propios de la posmodernidad, particularmente la deconstrucción" (Salías, 2014, p. 1). La muestra estuvo dividida en cuatro conceptos que respondieron al $A D N$ de cada diseñador y agrupados en un recorrido de los primeros años del nuevo milenio. Hasta el momento, esta fue la única exhibición de moda que distinguió el movimiento denominado Diseño de Autor gestado tras la crisis de 2001 y contó como canales principales de comunicación y comercialización a Bafweek y Palermo Viejo. En modo solista, un año después, Pablo Ramírez presentó Magia Negra (2014) en la Fundación Osde de Rosario y Buenos Aires, bajo la curaduría de María Laura Carrascal, quien también estuvo a cargo de la muestra de Varanasi, y la diseñadora Mariana Cortés reunió su repertorio en Juana de Arco, 20 años (2018) en el Museo del Traje. En 2021 está planificada una intervención de la dupla Trosman Churba en las instalaciones del Museo de Arte Moderno de Buenos Aires. 


\section{MALBA MODA}

Entre los años 2003 y 2007, el Museo de Arte Latinoamericano de Buenos Aires, dedicó un área al diseño y a la moda. Así, el MALBA presentó cuatro propuestas que articularon el arte y la moda en una experiencia en común. ¿Qué le pasa a la moda cuando entra en el museo? ¿Cuáles son sus límites? ¿Cuáles son sus transformaciones? ¿Cómo se relacionan el cuerpo, el vestido y el espacio? Estos son los interrogantes que sucedieron, con el desfile como herramienta en común, en la búsqueda de su propio espacio público.

Hábito Malba. 4 Actos (2003) contó con Andrea Saltzman como curadora invitada de esta serie de desfiles donde fueron citados Sergio De Loof, Martín Churba, Brandazza de Aduriz y Vero Ivaldi para desarrollar un proyecto que invocara la relación entre el cuerpo, el vestido y el espacio.

Se trata de intervenir el Malba, habitándolo; apropiándose del espacio a partir de dicha acción. El vestido califica al cuerpo, le da una identidad y una significación. Al mismo tiempo, el cuerpo vestido y su accionar caracterizan al espacio brindándole un sentido y una nueva fisonomía. Cada acto dejará un diseño como rastro. Quedará una huella de la historia compartida (Saltzman, 2003, p. 1).

Siguió Moda 04 | Estilos latinoamericanos (2004) con Victoria Lescano como curadora invitada y los desfiles del diseñador brasileño Alexandre Herchcovitch y los argentinos Kelo Romero, perteneciente a la camada de diseñadores que operaron en torno al Bar Bolivia y Araceli Pourcel, diseñadora de la generación del movimiento de autor y de la Facultad de Diseño, Arquitectura y Urbanismo, Universidad de Buenos Aires. Moda en Progresión (2005) reunió el trabajo de Rosita Bailón y el de dos generaciones de jóvenes diseñadores: Gabriel Grippo y Pablo Ramírez. Ana Torrejón ofició de curadora invitada.

Sea mediante la performance o mediante la instalación, los procesos creativos de Bailón, GGrippo y Ramírez tienen mucho de ritual; son ejercicios donde los objetos y elementos pertenecientes a la moda se reelaboran, conceptualizan y se presentan bajo los géneros o resoluciones del arte (Torrejón, 2005, p. 9).

El tiempo en Moda en Progresión fue organizado en las décadas del 70', 80’ y 90'. Grippo y Ramírez realizaron performances. Hubo una mesa que detalló el método de trabajo de GGrippo, gesto que tuvo su correlato cuando presentó Moda 1, 2, 3 (1992) en el CAyC -Centro de Arte y Comunicación- una muestra retrospectiva de su trabajo y método de reciclaje.

Grippo compuso un método propio de reciclaje que estuvo conectado en el tiempo con el del diseñador belga Martin Margiela: ellos crearon diseños con objetos encontrados y los reasignaron como productos de moda. Gabriel Grippo diseñó con sobrantes de cueros para la confección de camperas, intervenía jeans, las hilachas y las costuras fueron visibles en las ropas, pintó a mano las 
prendas, hizo patchwork con retazos en forma de corazón y margaritas, con las frazadas confeccionó abrigos y selló su trabajo con la etiqueta Grippo-Producto Diseñado (Perez, 2020, p. 1).

Al lado del Di Tella, la Galería del Este tenía su propia musa: Rosita Bailón (1933-1999), la propietaria de la tienda Mme Frou-Frou que funcionó entre 1968 y 1980. La etiqueta tomó las referencias de la música, el cine y la literatura como método para experimentar el diseño ofrecidos en vestidos de satén, chiffon y percales con volados y grandes escotes donde colgaban flecos. Su seña reconocible eran las maxi camisas abiertas de mangas bouffantes y grandes cuellos realizados con estampas y colores vibrantes. Los collares de perro eran una opción para cerrar el look de esta musa de los poetas beat y creadora de extrañas modas, como la señalaban los medios de la época. Varios de esos vestidos conformaron la retrospectiva junto a un corto producido por Victoria Lescano y dirigido por Agustín Alberdi. El área de moda y diseño del Museo de Arte Latinoamericano de Buenos Aires se despidió con Moda con Identidad Criolla (2006/2007) una retrospectiva de Mary Tapia, antropóloga de la moda, curada por Felisa Pinto y Victoria Lescano. La muestra fue categorizada en tres bloques que contó con la exhibición de 17 trajes desde los comienzos de Tapia hasta el 2006 y un video en el que la autora contaba su método de trabajo y referencias estéticas. La segunda parte convocó a los artistas y diseñadores Medora Manero, Manuela Rasjido, Rosa Skiffic, Araceli Pourcel, Mariana Dappiano, Martín Churba y Juana de Arco para recopilar en un video- instalación los trajes de su autoría que abordaban la estética folk. El tercer bloque reunió a diez diseñadores, Marcelo Ortega, Valeria Pesqueira, Rodrigo Abarquero, Celedonio Loitegui y Pablo Ramirez, para desarrollar piezas interviniendo accesorios camperos, como ponchos y alpargatas.

Así, la moda argentina se reúne en un archivo vivo y accesible que muestra su evolución en el museo y en diálogo permanente con el público. Aunque queda mucho por hacer.

\section{Bibliografía}

Anderson, F. (2000). Museums as Fashion Media. In Fashion Cultures: Theories, Explorations and Analysis. Londres: Ed. Routledge.

Business of Fashion. (2013). Recuperado de: https://www.businessoffashion.com/articles/ technology/digital-scorecard-valentino-garavani-virtual-museum

Colbert, F. (1999). Marketing Culture and the Arts. Nuevo Hampshire: Paul \& Co Pub Consortium.

Garcés, D. (1999). Exposición homenaje a Fridl Loos - Alta Costura. Fotogramas. Pinturas. Archivo Fundación IDA. Buenos Aires: Centro Cultural Recoleta

Koda, H. \& Glasscock, J. (2014). The costume institute at the Metropolitan Museum of art: An evolving history. Disponible en: https://www.metmuseum.org.

Loos, F. (1999). Exposición homenaje a Fridl Loos - Alta Costura. Fotogramas. Pinturas. Archivo Fundación IDA. Buenos Aires: Centro Cultural Recoleta

Marchan Fiz, S. (1982). La estética en la cultura moderna. Madrid: Alianza Editorial. 
Melchior, M. R. (2014). Fashion and museums: Theory and practice. Londres: Ed. Bloomsbury Academic.

Moragues, J. (2013). De Gino Bogani al diseño de Autor. Buenos Aires: Centro Cultural Recoleta

Pérez, L. (2016). Magia negra exhibición: un recorrido por la muestra de Pablo Ramírez y Val $\&$ Musso. Disponible en: http://www.blocdemoda.com/2016/04/magianegraexhibicion -pablo-ramirez-val-musso-moda-museo.html

Pérez, L. (2018). La Nación. Buenos Aires, Argentina: La Nación Moda. Recuperado de https://www.lanacion.com.ar/moda-y-belleza/como-cine-arte-moda-tambien-tienesus-nid2210048

Pérez, L. (2020). El Di Tella: punto de encuentro de arte y moda. Buenos Aires: LN Revista. Disponible en: https://www.lanacion.com.ar/moda-y-belleza/el-di-tella-punto-encuentro -arte-moda-nid2460200

Pérez, L. (2020). La Nación. Buenos Aires, Argentina: La Nación Moda. Recuperado de https:// www.lanacion.com.ar/moda-y-belleza/grippo-el-argentino-radicado-brooklyn-fue-pio nero-nid2321380

Pérez, L. (2020). Vanguardistas del Diseño de Autor. Buenos Aires: LN Revista. Disponible en: https://www.lanacion.com.ar/moda-y-belleza/vanguardistas-del-diseno-autornid2350131

Pérez, L. (2019). Los 20 años de Juana de Arco están en el museo. Disponible en: http://www. blocdemoda.com/2019/01/los-20-anos-de-juana-de-arco-museo-moda.html

Rodriguez, C. (2013). De Gino Bogani al diseño de Autor. Buenos Aires: Centro Cultural Recoleta.

Salias, V. (2014). Universos de moda. Buenos Aires: Colección de Arte Amalia Fortabat.

Saltzman, A. (2003). Hábito Malba. 4 Actos. Archivo Malba. Buenos Aires: Malba.

Se inauguró en Malba Moda en Progresion GGrippo-Bailon-Ramirez. (2005). Palermo Online. (2005). Recuperado el 08/12/2005 de https://palermonline.com.ar/noticias002/ nota325_modamalba.htm

Silverman, D. (1986). Selling Culture. Nueva York: Pantheon.

Steele, V. (2008). Fashion Theory, Museum Quality. Londres: Oxford International Publishers Ltd. Dba Berg Publishers.

Valentino. (2013). Italia. Recuperado de http://www.valentinogaravanimuseum.com

\begin{abstract}
Fashion had a more frequent appearance in museums and spaces for the exhibition of art in recent years. In the fashion shows, the culture of the past and present is collected, exhibited and investigated. This essay narrates the interest of museums in fashion and puts the experience of Argentine fashion in context, with references to exhibitions by Fridl Loos, Dalila Puzzovio, Mary Tapia, Gino Bogani, the under movement, the generation of author design and the case of Malba Moda in order to explore the potential of fashion in museums to reflect on history through the ages and its creators.
\end{abstract}


Keywords: fashion - art - museum - fashion communication - Argentina - author - design - history - creators - exhibitions.

Resumo: A moda teve um aparecimento mais frequente em museus e espaços de exposição de arte nos últimos anos. Nos desfiles, a cultura do passado e do presente é coletada, exibida e investigada. Este ensaio narra o interesse dos museus pela moda e contextualiza a experiência da moda argentina, com referências a exposições de Fridl Loos, Dalila Puzzovio, Mary Tapia, Gino Bogani, o submovimento, a geração do design autor e o caso da Malba Moda como forma de explorar as potencialidades da moda nos museus para refletir sobre a história ao longo dos tempos e seus criadores.

Palavras chave: moda - arte - museu - comunicação da moda - Argentina - autor - design - história - criadores - exposições.

[Las traducciones de los abstracts fueron supervisadas por el autor de cada artículo] 